\title{
Collateral damage of COVID-19 pandemic on oncology clinical trials
}

\author{
Sri Harsha Tella, Anuhya Kommalapati, Steve R. Alberts, Robert McWilliams, Amit Mahipal \\ Department of Medical Oncology, Mayo Clinic, Rochester, MN, USA \\ Correspondence to: Amit Mahipal, MBBS, MPH. Department of Oncology, Mayo Clinic, 200 1st street SW, Rochester MN 55906, USA. \\ Email: Mahipal.amit@mayo.edu.
}

Submitted Oct 12, 2020. Accepted for publication Oct 26, 2020.

doi: $10.21037 / \mathrm{cco}-20-200$

View this article at: http://dx.doi.org/10.21037/cco-20-200

Over the past decades, tremendous advancements in cancer care have translated into a substantial decline in disease-specific mortality rates $(1,2)$. As the physicians and researchers continue to work on improving the cancerrelated mortality, we are hindered by the global pandemic coronavirus disease 2019 (COVID-19) caused by severe acute respiratory syndrome coronavirus 2 (SARS-CoV-2). Despite the fact that clinical trials are integral part of cancer care delivery that translated to decreased mortality (3), institutions across the globe temporarily halted clinical trial enrollment. There are many unanswered questions now: how long can we postpone enrollment of new individuals with cancer onto clinical trials? There is a fair chance that a considerable number of individuals may never be eligible for participation in clinical trials if their cancer progresses in the interim. In fact, some of the clinical trials have restrictions on prior lines of anticancer treatment and patients' eligibility may be hampered by receipt of the standard of care therapies. The impact of such policies is not yet known, and is impossible to predict at this early time-point, but are likely to be substantial. Although halting the enrollment onto clinical trials is for public safety, it may not be welcoming news for the individuals with cancer, their families, and to the field of oncology. For the majority of patients with cancer, the priority remains the treatment of their underlying malignancy. If patients receive suboptimal therapy for their malignancy, there could be an increase in deaths indirectly related to the effects of COVID-19.

Fortunately, many institutions across the globe are in the process of opening up clinical trials as medical facilities are adapting to this "new normal" health care delivery. In the early days of the pandemic, there was a critical need for volunteers among the health care workers that led to shifting the majority of the workforce to the front lines taking care of patients with COVID-19. While the pandemic has crossed the peak at some parts of the globe, health care professionals and medical researchers have worked on placing new protocols in place for better safety of health care workers and patients visiting medical facilities. It is most likely the case that hospitals are able to handle the COVID-19 challenges better compared to a couple of months ago.

Herein we discuss some potential solutions that could potentiate the early opening of clinical trial options for oncology patients (Table 1). For any patient who chooses to participate in a clinical trial, SARS-CoV-2 antigen testing using a reverse transcription polymerized chain reaction (rtPCR) technique should be offered at the beginning of a clinical trial and prior to every cycle, especially while receiving immunosuppressive agents that have high propensity to cause neutropenia. The choice of the primer used in rtPCR assay is country specific. For instance, in the United States the standard practice is testing for three targets in nucleocapsid protein $(\mathrm{N})$ of the virus genome whereas Germany uses envelop (E) and N proteins (4). The rtPCR testing should be offered to asymptomatic patients too as a recent single-institution study showed $8 \%$ of cancer patients had a positive SARS-CoV-2 PCR test before they developed symptomatic COVID-19 (5). It is important to note that mutations occur frequently in SARS$\mathrm{CoV}-2$ and this could potentially cause false negatives in the diagnosis of COVID-19. The sensitivity of the rtPCR test may be increased by evaluating $>1$ proteins in the viral genome. Though there are no specific consensus 
Table 1 Potential barriers and possible solutions for clinical trial enrollment during COVID-19 pandemic

\begin{tabular}{|c|c|}
\hline Potential barriers & Possible solutions \\
\hline \multicolumn{2}{|l|}{ Medical facility-related } \\
\hline \multirow[t]{2}{*}{ Health care personnel safety } & Universal precautions: masking and handwashing \\
\hline & Daily screening for symptoms at the entrance of the medical facility \\
\hline \multirow[t]{2}{*}{ Limited workforce } & $\begin{array}{l}\text { Virtual visits should be encouraged if no specific trial intervention is } \\
\text { needed }\end{array}$ \\
\hline & Prioritizing phase 2 and 3 clinical trials \\
\hline $\begin{array}{l}\text { Lack of detailed knowledge on the impact of COVID-19 on cancer } \\
\text { care delivery }\end{array}$ & $\begin{array}{l}\text { Encouraging surveys and crowdsourcing to better understand the } \\
\text { potential barriers in the care and coming up with possible solutions }\end{array}$ \\
\hline \multicolumn{2}{|l|}{ Therapy-related } \\
\hline \multirow{3}{*}{$\begin{array}{l}\text { Immunotherapies such as checkpoint inhibitors, CAR-Ts, and } \\
\text { bi-specific T-cell antibodies; bone marrow suppressive } \\
\text { chemotherapy; multiple visits for correlative studies and research } \\
\text { sampling }\end{array}$} & $\begin{array}{l}\text { Extreme caution should be employed while enrolling patients on } \\
\text { specific clinical trials }\end{array}$ \\
\hline & Enrolling patients who needs immediate treatment only \\
\hline & $\begin{array}{l}\text { Immediate medical attention recommended in case of fever, } \\
\text { respiratory illness, or sore throat }\end{array}$ \\
\hline \multicolumn{2}{|l|}{ Patient-related } \\
\hline \multirow{3}{*}{$\begin{array}{l}\text { Safety, traveling long-distances, especially during this travel } \\
\text { disruption and economic burden }\end{array}$} & Following "spoke and hub" design \\
\hline & Performing laboratory investigations near home \\
\hline & $\begin{array}{l}\text { Undergoing imaging studies locally and uploading in central } \\
\text { database }\end{array}$ \\
\hline
\end{tabular}

guidelines on routine SARS-CoV-2 screening in cancer patients, this could potentially prevent future catastrophic complications especially in the patients receiving bone marrow suppressive therapy. Individual risk and benefit should be discussed in detail with the patients and shared decision making should be used at the time of enrollment on a clinical trial. This is particularly important in patients receiving immunotherapy and chemotherapy agents that have a high propensity to cause bone marrow toxicity and neutropenia. Immunotherapy with immune checkpoint 
inhibitors potentiates the host's immune response to target tumor cells. While SARS-CoV-2 is known to cause vascular endothelium damage leading to COVID-19-related acute respiratory distress syndrome (ARDS) (6), the situation may get complicated in the setting of "immune upregulation" caused by checkpoint inhibitors. As immune checkpoint inhibitors are known to cause pneumonitis (7), we should employ a very low threshold for SARS-CoV-2 testing and appropriate imaging studies in patients who develop respiratory symptoms. In addition, extreme caution should be employed when accruing patients to the clinical trials involving chimeric antigen receptor (CAR) T-cell therapy and other agents such as cancer vaccines and bi-specific T-cell antibodies that may trigger immune-activation and cytokine release syndrome (CRS) (8).

Secondly, participating institutions should have a discussion with the trial sponsors and determine if research only sampling for blood and tissue is absolutely necessary. Lack of correlative data for the proportion of patients on a trial may be acceptable as long as trial primary endpoints are not jeopardized. Phase 2 and phase 3 trials may have more leeway in this regard. For phase 1 trials, this may be more challenging as patients often require multiple visits and lab testing for safety reasons. In addition, clinical trials with a dose-escalation phase will require more stringent follow up for patients' safety as well as mandatory pharmacodynamic and pharmacokinetic sampling. Therefore, with the availability of limited resources, priority should be given to phase 1 clinical trials that are in dose-expansion phase. Accrual to phase 1 trials in a dose-escalation stage may need to be delayed. Special emphasis can be given on biomarkerdriven trials and allowing patients to enroll who are biomarker positive for that specific clinical trial.

Although medical teams are preparing themselves to provide uninterrupted care to patients with cancer, the major challenge would be patient "hesitancy" to visit the health care facility. It is not uncommon that oncology patients travel long distances to participate in clinical trials due to their availability at a particular facility. To have better patient participation and reduce patients' exposure to SARS-CoV-2-one option would be encouraging the "spoke and hub" design where the specific details and consent of the clinical trials can be done virtually and the drug delivery, investigations, and imaging studies may be performed at various satellite centers (9). While this sounds theoretically feasible, it opens up many challenging questions such as reliability and variability among different personnel at the various sites, including adherence to protocol specified activities. One possible solution for this would be having well-trained personnel at all the trial locations and having periodic refresher courses to reinforce reliability and ethical conduct. Another option is that all the laboratory investigations can be performed at a local laboratory center and imaging studies will be uploaded to a central station where dedicated radiologists read the images (10). In addition, the research team should evaluate the possibility of oral study drug delivery by mail to the patients directly for athome administration (10). It is important to discuss the drug administration in detail with the patient by the research team through a virtual visit with special emphasis on compliance.

As we collectively fight the COVID-19 pandemic, societies such as the American Society of Clinical Oncology (ASCO), American Society of Hematology, European Society of Medical Oncology (ESMO), COVID-19 and cancer consortium (CCC19) initiated registries to better understand the impact of COVID-19 on cancer care delivery and how the practices have changed due to the pandemic. Analyses of the data would potentially help us in filling the gaps in the clinical trial enrollment so that we can hope for a better tomorrow in cancer care and research.

\section{Acknowledgments}

Funding: None.

\section{Footnote}

Provenance and Peer Review: This article was a free submission to the journal. The article was sent for external peer review.

Conflicts of Interest: All authors have completed the ICMJE uniform disclosure form (available at http://dx.doi. org/10.21037/cco-20-200). The authors have no conflicts of interest to declare.

Ethical Statement: The authors are accountable for all aspects of the work in ensuring that questions related to the accuracy or integrity of any part of the work are appropriately investigated and resolved.

Open Access Statement: This is an Open Access article distributed in accordance with the Creative Commons Attribution-NonCommercial-NoDerivs 4.0 International License (CC BY-NC-ND 4.0), which permits the noncommercial replication and distribution of the article with 
the strict proviso that no changes or edits are made and the original work is properly cited (including links to both the formal publication through the relevant DOI and the license). See: https://creativecommons.org/licenses/by-nc-nd/4.0/.

\section{References}

1. Siegel RL, Miller KD, Jemal A. Cancer statistics, 2020. CA Cancer J Clin 2020;70:7-30.

2. Society AAC. Cancer Mortality Milestone: 25 years of Continuous Decline. 2020.

3. Unger JM, Cook E, Tai E, et al. The Role of Clinical Trial Participation in Cancer Research: Barriers, Evidence, and Strategies. Am Soc Clin Oncol Educ Book 2016;35:185-98.

4. Abduljalil JM. Laboratory diagnosis of SARS-CoV-2: available approaches and limitations. New Microbes New Infect 2020;36:100713.

5. Al-Shamsi HO, Coomes EA, Alrawi S. Screening for COVID-19 in Asymptomatic Patients With Cancer in

Cite this article as: Tella SH, Kommalapati A, Alberts SR, McWilliams R, Mahipal A. Collateral damage of COVID-19 pandemic on oncology clinical trials. Chin Clin Oncol 2020;9(6):80. doi: 10.21037/cco-20-200 a Hospital in the United Arab Emirates. JAMA Oncol 2020;6:1627-8.

6. Marini JJ, Gattinoni L. Management of COVID-19 Respiratory Distress. JAMA 2020;323:2329-30.

7. Nishino M, Giobbie-Hurder A, Hatabu H, et al. Incidence of Programmed Cell Death 1 InhibitorRelated Pneumonitis in Patients With Advanced Cancer: A Systematic Review and Meta-analysis. JAMA Oncol 2016;2:1607-16.

8. Bonifant CL, Jackson HJ, Brentjens RJ, et al. Toxicity and management in CAR T-cell therapy. Mol Ther Oncolytics 2016;3:16011.

9. Elrod JK, Fortenberry JL Jr. The hub-and-spoke organization design: an avenue for serving patients well. BMC Health Serv Res 2017;17:457.

10. Doherty GJ, Goksu M, de Paula BHR. Rethinking cancer clinical trials for COVID-19 and beyond. Nat Cancer 2020. [Epub ahead of print]. doi: 10.1038/s43018-0200083-x. 